\title{
Phosphorylation-Dependent Trafficking of GluR2- Containing AMPA Receptors in the Nucleus Accumbens Plays a Critical Role in the Reinstatement of Cocaine Seeking
}

\author{
Katie R. Famous, ${ }^{1}$ Vidhya Kumaresan, ${ }^{1}$ Ghazaleh Sadri-Vakili, ${ }^{3}$ Heath D. Schmidt, ${ }^{1}$ Dale F. Mierke, ${ }^{4}$ Jang-Ho J. Cha, ${ }^{3}$ \\ and R. Christopher Pierce ${ }^{1,2}$ \\ Departments of ${ }^{1}$ Pharmacology and ${ }^{2}$ Psychiatry, Boston University School of Medicine, Boston, Massachusetts 02118, ${ }^{3}$ Department of Neurology, \\ MassGeneral Institute for Neurodegenerative Disease, Massachusetts General Hospital, Charlestown, Massachusetts 02129, and ${ }^{4}$ Department of Chemistry, \\ Dartmouth College, Hanover, New Hampshire 03755
}

\begin{abstract}
A growing body of evidence indicates that enhanced AMPA-mediated glutamate transmission in the core of the nucleus accumbens is critically involved in cocaine priming-induced reinstatement of drug seeking, an animal model of relapse. However, the extent to which increased glutamate transmission in the other major subregion of the nucleus accumbens, the shell, contributes to the reinstatement of cocaine seeking remains unclear. In the present experiments, administration of the AMPA/kainate receptor antagonist CNQX $(0,0.03$, or $0.3 \mu \mathrm{g})$ into either the core or the shell of the nucleus accumbens before a systemic cocaine priming injection (10 mg/kg, i.p.) dosedependently attenuated the reinstatement of drug seeking. Cocaine priming-induced reinstatement of cocaine seeking also was associated with increases in GluR2-pSer880 in the nucleus accumbens shell. The phosphorylation of GluR2 by PKC at Ser880 plays an important role in the trafficking of GluR2-containing AMPA receptors from the plasma membrane. The current results showed that administration of a cell-permeable peptide that disrupts GluR2 trafficking (Pep2-EVKI) into either the accumbens core or shell attenuated cocaineinduced reinstatement of drug seeking. Together, these findings indicate that changes in AMPA receptor-mediated glutamate transmission in both the nucleus accumbens core and shell are necessary for the reinstatement of drug seeking induced by a priming injection of cocaine. The present results also demonstrate that the reinstatement of cocaine seeking is associated with increases in the phosphorylation-dependent trafficking of GluR2-containing AMPA receptors in the nucleus accumbens.
\end{abstract}

Key words: relapse; addiction; psychostimulant; glutamate; CNQX; Pep2-EVKI

\section{Introduction}

Enhanced AMPA receptor-mediated glutamate transmission in the nucleus accumbens plays a central role in the reinstatement of cocaine seeking (Kalivas et al., 2005; Schmidt et al., 2005). For example, administration of an AMPA receptor agonist directly into the nucleus accumbens reinstates cocaine seeking, whereas intra-accumbal administration of an AMPA receptor antagonist attenuates the reinstatement of drug seeking induced by a cocaine priming injection (Cornish and Kalivas, 2000). The nucleus accumbens is anatomically and functionally heterogeneous in that this structure can be divided into two major subregions known as the core and shell (Heimer et al., 1997). Although there is evi-

\footnotetext{
Received March 20, 2008; revised Sept. 17, 2008; accepted Sept. 19, 2008.

This work was supported by National Institutes of Health (NIH) Grants R01 DA22339, R01 DA15214, K02 DA18678 (R.C.P.), and R01 DA18428 (D.F.M.). K.R.F. was partially supported by a National Research Service Award (NRSA) from the NIH (F30 DA19304), as well as NIH Training Grant T32 GM008541-7. H.D.S. was also partially supported by a NRSA from the NIH (DA16824). J.-H.J.C. and G.S.V. received support from the Glendorn Foundation. We thank Audrey Pierce for administrative assistance and Dr. Marina Wolf for comments on previous versions of this manuscript.

Correspondence should be addressed to R. Christopher Pierce at his present address: Department of Psychiatry, University of Pennsylvania School of Medicine, 125 South 31st Street, Philadelphia, PA 19104. E-mail: rcpierce@mail.med.upenn.edu.

DOI:10.1523/JNEUROSCI.1221-08.2008

Copyright $\odot 2008$ Society for Neuroscience $\quad$ 0270-6474/08/2811061-10\$15.00/0
}

dence that increased glutamate transmission in the nucleus accumbens core promotes the reinstatement of cocaine seeking (McFarland et al., 2003), the respective roles of core and shell AMPA receptors in priming-induced reinstatement of cocaine seeking have not been assessed systematically (Park et al., 2002).

AMPA receptors are tetrameric and can be composed of four different subunits termed GluR1-4. Virtually all medium spiny neurons in the nucleus accumbens express GluR1 and GluR2 receptor subunits; in contrast, GluR3 and GluR4 subunits are expressed in the nucleus accumbens at low and very low levels, respectively (Bernard et al., 1997; Gold et al., 1997; Boudreau et al., 2007). Increases in nucleus accumbens GluR1, GluR2 and GluR2/3 have been observed after days to weeks of forced abstinence after cocaine self-administration ( $\mathrm{Lu}$ et al., 2003; Tang et al., 2004) or in conjunction with the extinction of cocaine selfadministration behavior (Sutton et al., 2003). For example, the increase in nucleus accumbens GluR2 after cocaine selfadministration was observed 1 and $30 \mathrm{~d}$ after the last day of cocaine self-administration ( $\mathrm{Lu}$ et al., 2003). Interestingly, GluR2/3 levels also are increased in the nucleus accumbens of cocaine overdose victims (Hemby et al., 2005). In these experiments, changes in the phosphorylation state of AMPA receptor subunits were not determined. Moreover, changes in AMPA re- 
ceptor subunit phosphorylation in the major subregions of the accumbens, the core and shell, after cocaine self-administration have not been assessed previously.

Trafficking of AMPA receptors to the plasma membrane is also influenced by a history of cocaine exposure. Thus, three weeks, but not one day, after the last of a series of repeated cocaine injections there was an increase in the ratio of surface to intracellular GluR1 and GluR2/3 AMPA receptor subunits in the nucleus accumbens (Boudreau and Wolf, 2005). These results suggest that increased synaptic expression of GluR1, GluR2 and possibly GluR3 receptor subunits in the nucleus accumbens contribute to cocaine-induced behavioral plasticity.

The present study had three goals: (1) to assess the effect of administration of an AMPA/kainate receptor antagonist directly into the nucleus accumbens core or shell on cocaine priminginduced reinstatement of cocaine seeking; (2) to determine the effect of cocaine priming-induced reinstatement on the expression of GluR2-pSer880 in the accumbens core and shell; and (3) to evaluate the role of accumbal GluR2-containing AMPA receptor trafficking in the reinstatement of cocaine-seeking behavior. Our results indicate that phosphorylation-induced trafficking of GluR2-containing AMPA receptors in the nucleus accumbens plays a critical role in cocaine priming-induced reinstatement of drug seeking.

\section{Materials and Methods}

Animals and housing. Male Sprague Dawley rats (Rattus norvegicus) weighing 250-300 g were obtained from Taconic Laboratories. Animals were individually housed, with food and water available ad libitum in the home cage (rats undergoing food reinstatement were placed on restricted diets, as outlined below). A $12 \mathrm{~h}$ light/dark cycle was used with the lights on at 7:00 A.M. All experimental procedures were performed during the light cycle. The experimental protocols were all consistent with the guidelines issued by the U.S. National Institutes of Health and were approved by the Boston University School of Medicine Institutional Animal Care and Use Committee.

Materials. All experiments used Med-Associates modular testing instrumentation enclosed within ventilated, sound attenuating chambers. The apparatus was equipped with response levers, stimulus lights, a food pellet dispenser and injection pump for infusing drugs intravenously.

Surgery. Before surgery, rats were anesthetized with $80 \mathrm{mg} / \mathrm{kg}$ ketamine and $12 \mathrm{mg} / \mathrm{kg}$ xylazine. An indwelling SILASTIC catheter (inner diameter, $0.33 \mathrm{~mm}$; outer diameter, $0.64 \mathrm{~mm}$ ) was inserted into the right jugular vein (side opposite the heart) and sutured in place. The catheter was then threaded subcutaneously over the shoulder blade and was routed to a mesh backmount platform (CamCaths) that secured the placement. Catheters were flushed daily with $0.3 \mathrm{ml}$ of the antibiotic Timentin (ticarcillin disodium/potassium clavulanate, $0.93 \mathrm{mg} / \mathrm{ml}$ ) dissolved in heparinized saline. The catheters were sealed with plastic obturators when not in use.

After catheter insertion, some animals were mounted in a stereotaxic apparatus and guide cannulas (14 mm, 24 gauge) for microinjections were implanted bilaterally $2 \mathrm{~mm}$ dorsal to the nucleus accumbens core or the medial nucleus accumbens shell. Cannulas were cemented in place by affixing dental acrylic to stainless steel screws secured in the skull. The coordinates for the ventral ends of the guide cannulas, relative to bregma according to the atlas of Paxinos and Watson (1997) were as follows: core, $+1.0 \mathrm{~mm}$ anterior/posterior $(\mathrm{A} / \mathrm{P}), \pm 2.5 \mathrm{~mm}$ medial/lateral $(\mathrm{M} / \mathrm{L})$, $-5.0 \mathrm{~mm} \mathrm{dorsal} /$ ventral $(\mathrm{D} / \mathrm{V})$; shell, $+1.0 \mathrm{~mm} \mathrm{~A} / \mathrm{P}, \pm 1.0 \mathrm{~mm} \mathrm{M} / \mathrm{L}$, $-5.0 \mathrm{~mm} \mathrm{D} / \mathrm{V}$. To prevent occlusion of the cannulas, an obturator (14 $\mathrm{mm}, 33$ gauge wire) was inserted into each guide cannula.

Cocaine self-administration and extinction. After surgery, rats were allowed $7 \mathrm{~d}$ to recover before behavioral testing commenced. Initially, rats were trained in operant chambers to lever press for intravenous cocaine ( $0.25 \mathrm{mg}$ cocaine $/ 59 \mu \mathrm{l}$ saline, infused over a $5 \mathrm{~s}$ period) on a fixed-ratio 1 (FR1) schedule of reinforcement. Each session began with the intrave- nous administration of $59 \mu \mathrm{l}$ cocaine $(0.25 \mathrm{mg})$ to fill the catheter (little or none of this noncontingent injection reached the systemic circulation). Rats were allowed to self-administer a maximum of 30 injections per 120 min operant session. When at least 20 infusions of cocaine in a session were achieved under the FR1 schedule, the subjects were switched to a fixed-ratio 5 (FR5) schedule of reinforcement. The maximum number of injections was again limited to 30 per daily self-administration session under the FR5 schedule. For both the FR1 and FR5 schedules, a 20 s time-out period followed each cocaine infusion, during which time active lever responses were tabulated but had no scheduled consequences. Responses made on the inactive lever, which had no scheduled consequences, were also recorded during both the FR1 and FR5 training sessions.

Daily operant sessions under the FR5 schedule of reinforcement were continued 5-6 d/week for a total of $21 \mathrm{~d}$ of cocaine self-administration on FR1 and FR5 schedules. Cocaine self-administration behavior was extinguished by replacing the cocaine with $0.9 \%$ saline. The extinction phase continued until responding on the active lever was $<15 \%$ of the response rate maintained by cocaine self-administration under the FR5 schedule of reinforcement.

Reinstatement. After extinction, animals entered the reinstatement phase of the experiment. During reinstatement, using a between-sessions paradigm, satisfaction of the response requirement resulted in saline rather than cocaine infusion (which was identical to extinction conditions). Each reinstatement session was followed by extinction sessions until responding was again $<15 \%$ of the response rate maintained by cocaine self-administration. Generally, $1-2 \mathrm{~d}$ were necessary to reach extinction criterion between reinstatement test sessions. The FR5 schedule was used throughout the extinction and reinstatement phases of these experiments.

The effect of intra-accumbal core or shell pretreatment with the AMPA/kainate receptor antagonist CNQX on cocaine priming induced reinstatement of drug seeking was assessed. Two doses of CNQX ( 0.03 or $0.3 \mu \mathrm{g} / 0.5 \mu \mathrm{l})$ or vehicle ( $0.9 \%$ saline) were microinjected bilaterally into the core or shell of the nucleus accumbens $10 \mathrm{~min}$ before a $10 \mathrm{mg} / \mathrm{kg}$ (intraperitoneal) priming injection of cocaine.

In a separate experiment we used a peptide corresponding to the last six amino acids of the $\mathrm{C}$ terminus of the GluR2 AMPA receptor subunit (i.e., IEEVKI). This peptide, which is known as Pep2-EVKI, interferes with the interaction between protein interacting with C-kinase (PICK1) and GluR2 AMPA receptor subunits (Li et al., 1999; Daw et al., 2000). The interaction between PICK1 and the GluR2 subunit is essential for the trafficking of AMPA receptors to and from the plasma membrane (Gardner et al., 2005; Liu and Cull-Candy, 2005; Hanley, 2006; Ziff, 2007). Using pull-down assays with GluR2, Pep2-EVKI has been shown to selectively and specifically interfere with the interaction between the GluR2 subunit and PICK1 (Li et al., 1999; Daw et al., 2000). Another peptide, IESVKE known as Pep2-SVKE, was developed as a control peptide for Pep2-EVKI; Pep2-SVKE has been shown to have no influence on the interactions between GluR2 and PICK1 or other GluR2 subunit binding partners (Li et al., 1999). To render Pep2-EVKI and Pep2-SVKE membrane permeable, they were conjugated to a modified tetrapeptide (TrpD-Arg-Phe-Lys) previously shown to be capable of transcellular translocation (Zhao et al., 2003). During the reinstatement phase of the experiment, Pep2-EVKI $(5 \mu \mathrm{g} / 0.5 \mu \mathrm{l})$, Pep2-SVKE $(5 \mu \mathrm{g} / 0.5 \mu \mathrm{l})$ or their saline vehicle was microinjected into the nucleus accumbens shell $1 \mathrm{~h}$ before a priming injection of $10 \mathrm{mg} / \mathrm{kg}$ cocaine (intraperitoneal). Pep2EVKI $(5 \mu \mathrm{g} / 0.5 \mu \mathrm{l})$ or its saline vehicle also was microinjected into the nucleus accumbens core $1 \mathrm{~h}$ before a priming injection of cocaine. A fluorescent analog of the membrane permeable form of Pep2-EVKI was generated by the substitution of Lys ${ }^{4}$ in the tetrapeptide sequence with a $\beta$-dansyl-L- $\alpha, \beta$-diaminopropionic acid. This fluorescent analog was used to demonstrate Pep2-EVKI transcellular translocation in vivo after microinjection.

Microinjection procedures. The obturators were removed from the guide cannulas and 33 gauge stainless steel microinjectors (Small Parts) were inserted. These microinjectors were cut to a length that extended 2 $\mathrm{mm}$ below the ventral end of the guide cannulas and into the accumbens core or shell. Bilateral infusions were performed simultaneously over a 
$120 \mathrm{~s}$ time period in a total volume of $0.5 \mu \mathrm{l}$ per side. After the microinjections, guide cannulas were left in place for $60 \mathrm{~s}$, to allow the solution to diffuse away from the tips of the cannulas, before they were removed. The goal of the experimental design was to have each animal serve as its own control and receive up to four microinjections per brain region. However, we were frequently forced to deviate from this experimental design when technical difficulties (i.e., blocked microinjection cannulas or loss of catheter patency) made it impossible to test all doses of a compound plus vehicle in an entire cohort of subjects. In every case, however, an animal received at a minimum treatment of one drug dose and its vehicle. To control for potential order effects of drug and vehicle administrations, all drug and vehicle treatments were counterbalanced across reinstatement sessions. However, the loss of some animals from an experiment because of technical difficulties may have compromised aspects of the counterbalanced design. Therefore, all subjects that failed to receive all of the scheduled microinjections underwent a final reinstatement session to confirm that the reinstatement response to a $10 \mathrm{mg} / \mathrm{kg}$ injection of cocaine remained robust.

Using this experimental design, the rats underwent a series of extinction and reinstatement sessions. During such repeated extinction sessions, extinction of the ability of cocaine to induce reinstatement is a concern. However, we have previously shown that reinstatement of cocaine seeking persists for at least $20 \mathrm{~d}$ after the initial extinction of cocaine self-administration (Park et al., 2002; Anderson et al., 2003). In all cases, the drug and vehicle treatments were counterbalanced across reinstatement days. All subjects demonstrated stable drug seeking throughout the reinstatement phase of these experiments. This was measured with systemic priming injections of cocaine $(10 \mathrm{mg} / \mathrm{kg}$, i.p.) at the beginning, middle and end of the reinstatement phase.

Food reinstatement. Potential nonspecific rate-suppressing effects of Pep2-EVKI were evaluated by assessing the influence of this compound on the reinstatement of food-reinforced responding. Rats were trained initially to press a lever under an FR1 schedule of sucrose pellet (Research Diets) delivery in daily $1 \mathrm{~h}$ sessions. The animals were restricted to 3 pieces of lab chow (Harlan Teklad) per day during self-administration and 2 pieces of chow per day (each piece of lab chow weighed $\sim 5.5 \mathrm{~g}$ ) during the reinstatement phase of these experiments. Water was continuously available in the home cage. Once animals acquired selfadministration on the FR 1 schedule ( $<15 \%$ variation in responding on 2 consecutive days), the rats were switched to an FR5 schedule of reinforcement. Subjects were limited to 30 sucrose pellets within a $1 \mathrm{~h}$ session.

After 2 weeks of food-maintained responding under an FR5 schedule, rats underwent an extinction phase where lever pressing no longer resulted in food delivery. After lever pressing decreased to $15 \%$ or less of the responding maintained by contingent food reinforcement, animals began reinstatement testing the following day. During the reinstatement phase, $1 \mathrm{~h}$ after Pep2-EVKI treatment, the animals were placed in the modular testing chambers and the session began with the issue of a noncontingent sucrose pellet prime. The experimenter remotely administered one sucrose pellet every $2 \mathrm{~min}$ thereafter for the first $10 \mathrm{~min}$ of the reinstatement session. Each reinstatement session was followed by extinction sessions until responding was again $<15 \%$ of the response rate maintained by food.

Verification of cannula placements. After the completion of all microinjection experiments, the animals were given an overdose of pentobarbital $(100 \mathrm{mg} / \mathrm{kg})$ and perfused intracardially with $0.9 \%$ saline followed by $10 \%$ formalin. The brain was removed and coronal sections $(100 \mu \mathrm{m})$ were taken at the level of the nucleus accumbens with a Vibratome (Technical Products International). The sections were mounted on gelatincoated slides and stained with cresyl violet. An individual unaware of behavioral responses determined cannula placements as well as excessive cannula-induced damage (defined as a cannula tract in excess of $500 \mu \mathrm{m}$ ) or drug-induced neurotoxicity (defined as cell death and gliosis extending beyond $100 \mu \mathrm{m}$ from the cannula tract). Animals with cannulas placements outside of the areas of interest, excessive mechanical damage or neurotoxicity were excluded from subsequent data analysis. In the CNQX and EVKI microinjection experiments, 22 and 19 animals were used, respectively, in the assessment of the reinstatement of cocaineseeking behavior. Eleven animals were removed from the data analysis because of faulty cannula placement and/or excessive mechanical damage and none because of neurotoxicity.

Drugs. Cocaine was obtained from the National Institute on Drug Abuse (Rockville, MD) and dissolved in bacteriostatic 0.9\% saline. CNQX (Sigma-Aldrich) was dissolved in sterile $0.9 \%$ saline. The doses of CNQX were selected based on previous reinstatement experiments involving microinjections into the nucleus accumbens (Cornish and Kalivas, 2000; Park et al., 2002).

Cocaine self-administration and yoked controls for Western blotting experiments. Rats underwent catheterization surgery as described above. After a $7 \mathrm{~d}$ recovery period from surgery, the rats were placed in the modular testing chambers (Med Associates) and trained using an FR1 schedule of reinforcement. Rats were assigned to one of five groups (selfadministration/challenge injection): cocaine/cocaine, cocaine/saline, yoked saline/cocaine, yoked saline/saline or yoked cocaine/cocaine. Within each individual experiment, rats were randomly assigned to experimental and control groups. Each rat trained to respond for contingent cocaine infusions was paired with a yoked subject that received infusions of saline or cocaine ( $0.25 \mu \mathrm{g}$, i.v. $)$. Lever pressing for the salineyoked rats had no scheduled consequences, but these animals received the same number and temporal pattern of infusions as self-administered by the paired cocaine-experimental rat.

When the cocaine-experimental animals achieved stable responding with the FR1 schedule, they were switched to an FR5 schedule. The rats were limited to a maximum of 30 cocaine infusions per daily $2 \mathrm{~h}$ selfadministration session. Daily operant sessions were conducted for a total of $14 \mathrm{~d}$. Cocaine self-administration was then extinguished as described above. After extinction, half of the cocaine self-administration rats and half of the yoked saline controls received $10 \mathrm{mg} / \mathrm{kg}$ cocaine (intraperitoneal), whereas the remaining animals received an injection of saline (intraperitoneal). All of the yoked cocaine rats received a challenge injection of $10 \mathrm{mg} / \mathrm{kg}$ cocaine intraperitoneally. All rats were then placed in the operant chambers under extinction conditions. Thirty minutes after the cocaine or saline injection, rats were removed from the operant chambers and immediately decapitated. The brain was then removed and the nucleus accumbens core and shell were dissected on ice. Brain tissue samples were stored at $-80^{\circ} \mathrm{C}$ until assayed via Western blotting.

Although this and other experiments in this study control for the influence of various extraneous variables, it should be acknowledged it is not possible to fully dissociate the pharmacological effects of cocaine that may not directly relate to the cocaine seeking. Future experiments could further address this issue by examining cocaine-seeking behavior under conditions where the primary reinforcer has not been introduced (e.g., cue- or stress-induced reinstatement of drug seeking).

Food self-administration and yoked controls for Western blotting experiments. The rats were restricted to three pieces of lab chow (Harlan Teklad) per day during self-administration and two pieces of chow per day during the reinstatement phase of these experiments; water was available ad libitum. Rats initially were trained to press a lever under an FR1 schedule of sucrose pellet (Research Diets) delivery in daily $1 \mathrm{~h}$ sessions. Yoked control rats received food in the same temporal pattern as the self-administration animals. Once animals acquired self-administration on the FR1 schedule (defined as $<15 \%$ variation in responding on 2 consecutive days), they were switched to an FR5 schedule of reinforcement. During the training phase, animals were limited to 30 pellets within a $1 \mathrm{~h}$ session. After $14 \mathrm{~d}$ of food-maintained responding, rats underwent an extinction phase where responding no longer resulted in food delivery. After lever pressing decreased to $15 \%$ or less of the responding maintained by contingent food reinforcement, reinstatement of food seeking was promoted by the noncontingent administration (remotely by the experimenter) of one sucrose pellet every 2 min during the first $10 \mathrm{~min}$ of the reinstatement session. Thirty minutes into the reinstatement session, rats were removed from the operant chambers and immediately decapitated. The brain was then removed and the nucleus accumbens core and shell were dissected on ice. Brain tissue samples were stored at $-80^{\circ} \mathrm{C}$ until assayed via Western blotting.

Western blotting. The brain tissue samples were homogenized with a Polytron (Brinkman Instruments) in ice-cold TEVP buffer (10 mM Tris$\mathrm{HCl}$, pH 7.4, 5 mm NaF, 1 mm Na $\mathrm{VO}_{4}, 1$ mm EDTA, 1 mm EGTA) and 
A.

\begin{tabular}{|ccc|}
\hline Cocaine Self-Administration & Extinction & Reinstatement \\
\hline 21 days & $\sim 7$ days & $\sim 20$ days \\
\hline
\end{tabular}

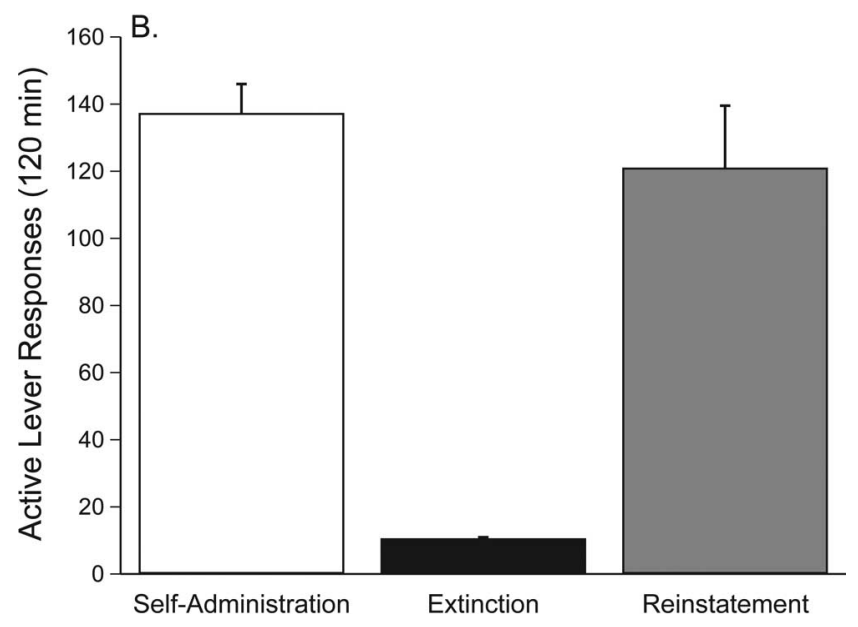

Figure 1. Cocaine priming-induced reinstatement of drug seeking. $A$, The reinstatement paradigm used in the current experiments involved $21 \mathrm{~d}$ of intravenous cocaine selfadministration ( $2 \mathrm{~h}$ per day) followed by daily extinction sessions until lever pressing decreased to $<15 \%$ of responding on the last day of cocaine self-administration. Rats required $\sim 1$ week to achieve this criterion. The reinstatement phase consisted of a series of reinstatement sessions each of which was followed by extinction that lasted a total of $\sim 20 \mathrm{~d}$. $\boldsymbol{B}$, These data represent active lever responses (mean \pm SEM) on the last day of cocaine self-administration and extinction as well as the reinstatement of cocaine seeking for the animals described in Figure $2 A$ that received a saline microinjection into the nucleus accumbens core before a systemic priming injection of cocaine during the reinstatement phase $(n=10)$.

sonicated for $8 \mathrm{~s}$. Protein content was determined with a Bio-Rad protein assay kit. $20 \mathrm{mg}$ aliquots were loaded onto $4-12 \%$ tris-glycine gels (Invitrogen) for the GluR proteins. The proteins were blotted to PVDF membranes and immunoprobed in 5\% milk (Bio-Rad) according to manufacturer's guidelines. An antibody to GluR2-pSer880 was obtained from Millipore. HRP conjugated secondary antibody dilutions were 1:10,000 (Bio-Rad). Bands were visualized using the ECL detection system (PerkinElmer Life and Analytical Sciences) and their intensities were quantified using computer-assisted densitometry (Alpha Innotech). For data analysis, all bands were normalized to GAPDH, divided by the mean of the control group for the appropriate brain region (and multiplied by 100) to facilitate comparison between brain regions.

Statistics. In terms of the behavioral data, we used a mixed factors design in which we aimed to administer each dose of a drug plus the drug vehicle to all subjects in a group during the reinstatement phase. However, technical difficulties (i.e., loss of catheter patency, clogging of guide cannulas, etc.) regularly result in at least one missing cell. Therefore, we used a statistical model (a mixed model multivariate ANOVA or MANOVA) that accommodates missing cells in the within-subjects aspect of an experimental design using the residual maximum likelihood approach (Berk, 1987). The Fisher's LSD $(p<0.05)$ post hoc test was used in all cases.

\section{Results}

\section{Cocaine priming-induced reinstatement of drug seeking}

The data depicted in Figure 1 show the last day of selfadministration, extinction and reinstatement of drug seeking induced by $10 \mathrm{mg} / \mathrm{kg}$ cocaine (intraperitoneal) for the experiment described in Figure $2 \mathrm{~A}$ (saline or CNQX microinjection into accumbens core before cocaine priming-induced reinstatement of drug seeking). After a total of $21 \mathrm{~d}$ of cocaine self-administration, all subjects entered the extinction phase during which selfadministration behavior was extinguished by replacing the cocaine with $0.9 \%$ saline. The extinction phase continued until re- sponding on the active lever was $<15 \%$ of the response rate maintained by cocaine self-administration under the FR5 schedule of reinforcement. For the animals whose data are depicted in Figure 1, the extinction criterion was reached in $5.8( \pm 0.663) \mathrm{d}$ on average. After extinction, reinstatement of cocaine seeking was precipitated by the administration of $10 \mathrm{mg} / \mathrm{kg}$ cocaine (intraperitoneal) to rats pretreated with saline in the accumbens core. Reinstatement of cocaine seeking was assessed at the beginning, middle and end of the reinstatement phase. Statistical analyses of these reinstatement data revealed no significant differences $\left(F_{(2,7)}=1.484, p<0.29\right)$, which indicated that the cocaine seeking response remained stable throughout the reinstatement phase.

\section{Microinjection of CNQX into the nucleus accumbens core or shell dose-dependently attenuated the reinstatement of cocaine seeking}

Animals were administered saline $(n=10)$ or $0.03 \mu \mathrm{g}(n=8)$ or $0.3 \mu \mathrm{g}(n=9)$ CNQX into the nucleus accumbens core or the medial nucleus accumbens shell (saline, $n=8 ; 0.03 \mu \mathrm{g}, n=4 ; 0.3$ $\mu \mathrm{g}, n=8$ ) before a priming injection of cocaine (10 $\mathrm{mg} / \mathrm{kg}$, i.p.) during the reinstatement phase. The total active and inactive lever presses during reinstatement after administration of saline or CNQX into the accumbens core before a systemic priming injection of cocaine are shown in Figure $2 A$. The total lever presses were analyzed with a two-way MANOVA, which revealed significant main effects of treatment $\left(F_{(2,24)}=5.185, p<0.0134\right)$ and lever $\left(F_{(1,24)}=69.628, p<0.0001\right)$ as well as a significant interaction between these factors $\left(F_{(2,24)}=6.849, p<0.0044\right)$. Subsequent pairwise analyses (Fisher's LSD, $p<0.05$ ) showed that the total active responses were significantly different between the saline and $0.3 \mu \mathrm{g}$ of CNQX treatments. The time courses of the active lever responses in the saline plus cocaine and $0.3 \mu \mathrm{g}$ of CNQX plus cocaine treatments into the core are summarized in Figure $2 \mathrm{~B}$. These data were analyzed with a mixed-factors MANOVA, with repeated measures over time. This analysis revealed significant main effects of treatment $\left(F_{(1,17)}=11.369, p<\right.$ $0.0036)$ and time $\left(F_{(11,7)}=12.288, p<0.0015\right)$ as well as a significant treatment $\times$ time interaction $\left(F_{(11,7)}=5.709, p<\right.$ 0.0147 ). Pairwise analyses (Fisher's LSD, $p<0.05$ ) showed a significant difference between the saline and $0.3 \mu \mathrm{g}$ of CNQX pretreatments during the 20 and 30 min time periods.

The total active and inactive lever presses during the reinstatement phase after administration of CNQX into the medial accumbens shell are shown in Figure 2C. The total active lever presses were analyzed with a two-way MANOVA, which revealed significant main effects of treatment $\left(F_{(2,44)}=10.117, p<\right.$ $0.0002)$ and lever $\left(F_{(1,44)}=118.023, p<0.0001\right)$ as well as a significant treatment $\times$ lever interaction $\left(F_{(2,44)}=11.022, p<\right.$ $0.0001)$. Post hoc analyses showed that the total active responses were significantly different between the saline and $0.3 \mu \mathrm{g}$ of CNQX treatments (Fisher's LSD, $p<0.05$ ). The time courses of the active lever responses in the saline plus cocaine and $0.3 \mu \mathrm{g}$ of CNQX plus cocaine treatments into the shell are summarized in Figure $2 D$. The time course data were analyzed with a mixedfactors MANOVA, with repeated measures over time. This analysis indicated a significant main effect of drug treatment $\left(F_{(1,14)}\right.$ $=7.143, p<0.0165)$ and time $\left(F_{(11,4)}=16.205, p<0.0081\right)$ as well as a significant treatment $\times$ time interaction $\left(F_{(11,4)}=5.898\right.$, $p<0.05)$. Pairwise analyses showed a significant difference between the saline and $0.3 \mu \mathrm{g}$ of CNQX pretreatments during the 10,20 and 30 min time periods (Fisher's LSD, $p<0.05$ ). Cannula placements in the nucleus accumbens core and shell from the 

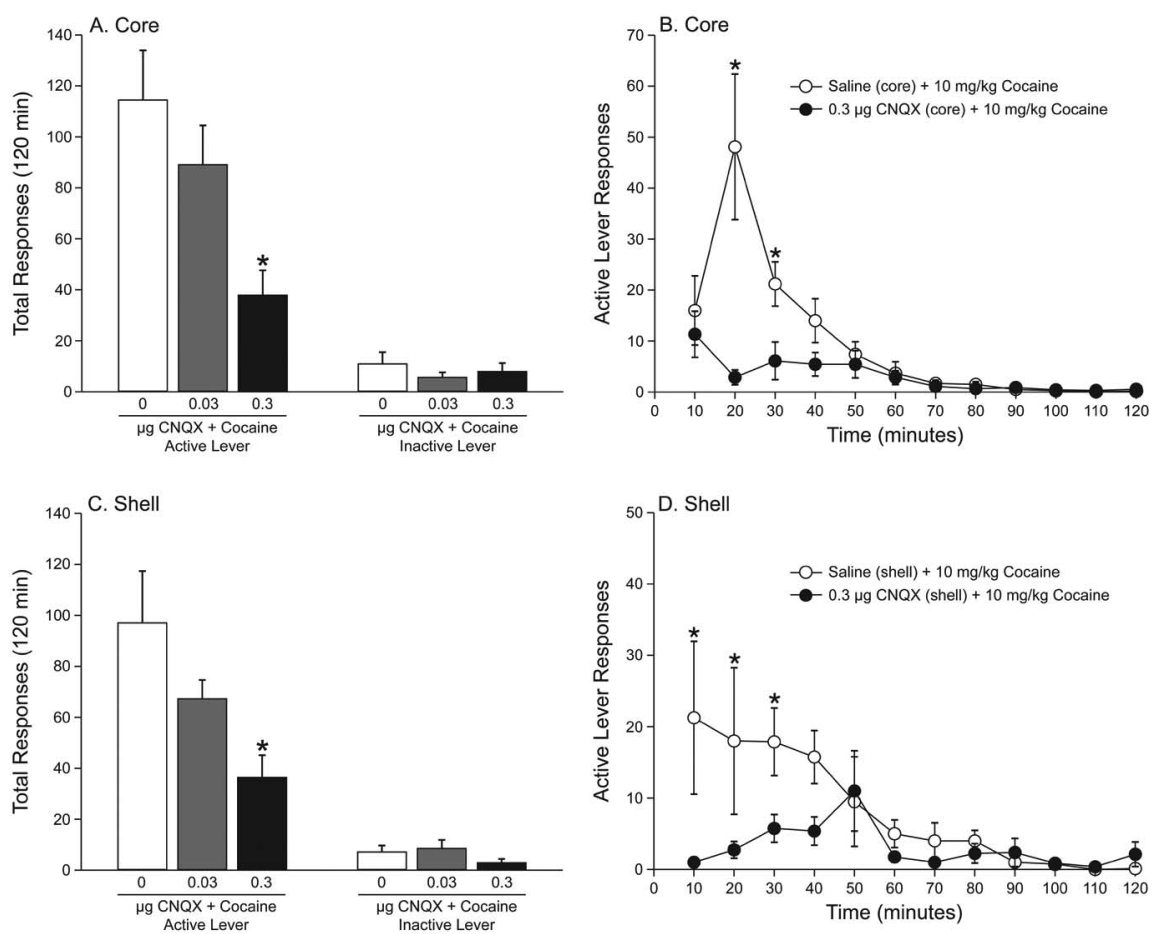

E.

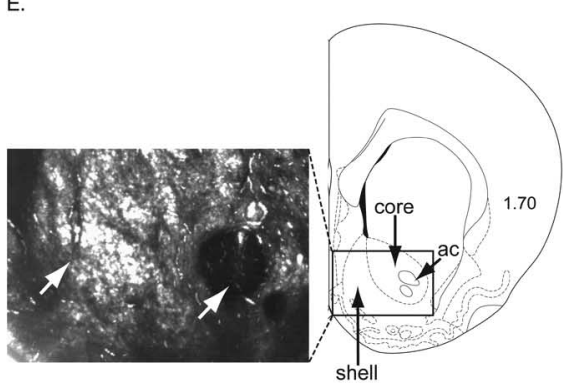

F.

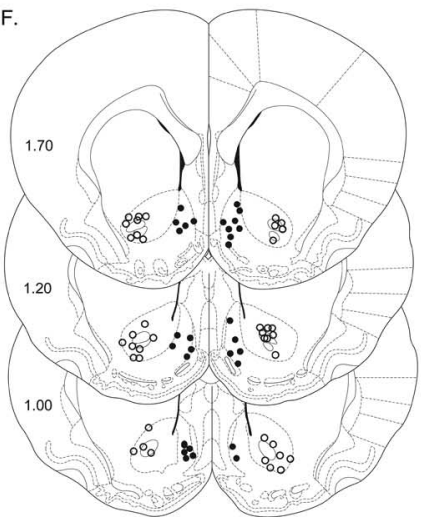

Figure 2. Administration of the AMPA/kainate receptor antagonist, CNQX, into the nucleus accumbens core or shell attenuates cocaine priming-induced reinstatement of cocaine seeking. $A$, Animals were administered saline $(n=10), 0.03 \mu \mathrm{g}(n=8)$ or 0.3 $\mu \mathrm{g}(n=9)$ CNQX into the nucleus accumbens core before a priming injection of cocaine $(10 \mathrm{mg} / \mathrm{kg}$, i.p.) during the reinstatement phase. The total (mean \pm SEM) active and inactive lever presses during the reinstatement phase after administration of CNQX into the accumbens core are shown. Note that the total active lever responses were significantly different between the saline and 0.3 $\mu \mathrm{g}$ of CNQX treatments. $\boldsymbol{B}$, Time courses of the reinstatement responses after administration of saline or $0.3 \mu \mathrm{g}$ of CNQX into the nucleus accumbens core before a systemic priming injection of cocaine. There was a significant difference between the saline and $0.3 \mu \mathrm{g}$ of CNQX pretreatments during the 20 and 30 min time periods. C, Animals were administered saline $(n=8), 0.03 \mu \mathrm{g}(n=$ 4) or $0.3 \mu \mathrm{g}(n=8)$ CNQX into the nucleus accumbens shell before a priming injection of cocaine (10 mg/kg, i.p.) during the reinstatement phase. Depicted are the total (mean \pm SEM) active and inactive lever presses during the reinstatement phase. Total active responses were significantly different between the saline and $0.3 \mu \mathrm{g}$ of CNQX treatments. $\boldsymbol{D}$, Time courses of the saline and $0.3 \mu \mathrm{g}$ of CNQX pretreatments from C. Note the significant difference between the saline and $0.3 \mu \mathrm{g}$ of CNQX pretreatments during the 10,20, and 30 min time periods. $\boldsymbol{E}$, Representative cannula placements in the nucleus accumbens core and shell. The right side is a schematic of a coronal brain section at the level of the anterior commissure (ac) from Paxinos and Watson (1997). The left side is a photomicrograph showing cannula tracts in the core and shell of the nucleus accumbens. The white arrows indicate the microinjection locations in the core (right arrow) and shell (left arrow). $\boldsymbol{F}$, Microinjection placements from all of the animals included in $\boldsymbol{A}-\boldsymbol{D}$. Filled circles represent microinjection locations in the nucleus accumbens shell; open circles represent placements in the nucleus accumbens core.

experiments summarized in Figure $2 A-D$ are presented in Figure $2 E, F$.

In our experience, the reinstatement of cocaine priminginduced drug seeking time course is typically similar to the response depicted in Figure $2 D$. In contrast, during the $20 \mathrm{~min}$ time period in Figure $2 B$ one rat displayed an atypically high response rate, which increased the mean and error during this period. Note that with the exception of the 20 min time period the time courses of the saline/cocaine responses in Figure $2 B, D$ are similar.

Several measures have been used to evaluate potential nonspecific rate suppressing effects of CNQX in reinstatement paradigms. The modular testing chambers were equipped with an inactive lever, responses on which often are used as a measure of nonspecific alterations in lever pressing during the reinstatement phase. Although CNQX did not have a significant influence on responding on the inactive lever, the low number of inactive lever presses limits the utility of this measure to meaningfully assess potential rate suppressant drug effects. However, previous studies indicated that the range of CNQX doses used in the present experiments had no effect on cocaine-induced behavioral hyperactivity (Cornish and Kalivas, 2000) and actually increased operant responding maintained by food (Maldonado-Irizarry et al., 1995; Park et al., 2002). These results indicate that intra-accumbal CNQX does not produce nonspecific rate-suppressing effects.

\section{The reinstatement of cocaine seeking was associated with increased GluR2- pSer880 in the nucleus accumbens}

In these experiments, after an average of approximately a week of extinction, subjects with a previous history of cocaine self-administration or yoked saline controls were administered $10 \mathrm{mg} / \mathrm{kg}$ cocaine or saline (intraperitoneal) and were allowed to self-administer saline under extinction conditions for $30 \mathrm{~min}$ at which point they were killed and their brains removed for the Western blot analyses. These data are summarized in Figure 3. As expected, animals with a history of cocaine self-administration showed robust reinstatement of cocaine seeking, whereas the yoked saline controls did not (data not shown). The nucleus accumbens core and shell dissections are shown in the diagram shown in Figure $3 A$. The densitometry results from the Western blots are shown in Figure 3, $B$ and $C$. Unpaired $t$ tests indicated that there was no significant difference in expression of GAPDH between the saline and cocaine groups in either the nucleus accumbens core or shell. All of the Western blot data were initially expressed as a ratio of GluR2pSer880/GAPDH and then presented as percentage of the control group. Figure 3, $B$ and $C$, depicts the GluR2-pSer880 data from the core and shell. These data were analyzed with a mixed factors ANOVA, with factors of self-administration (saline or cocaine) and reinstatement challenge (saline or cocaine) with repeated 


\section{A. Nucleus Accumbens Core \& Shell Dissections}

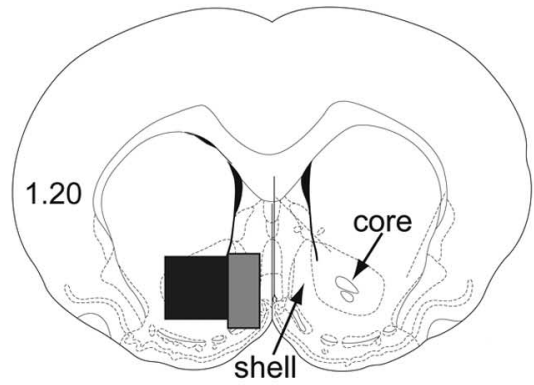

B. Core GluR2-pSer880
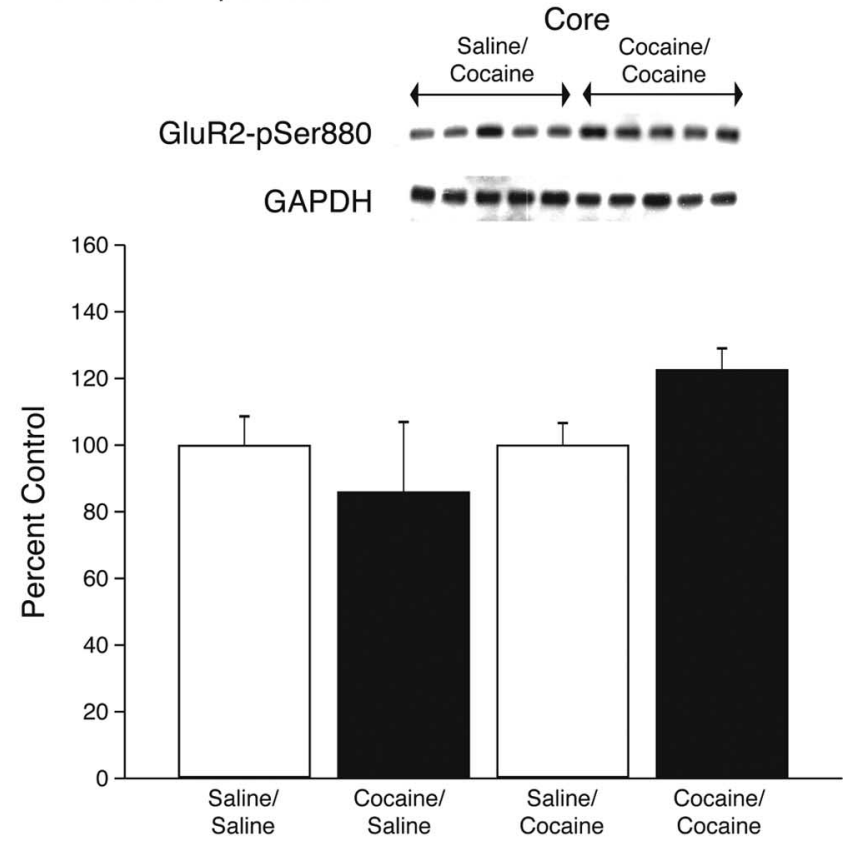

C. Shell GluR2-pSer880
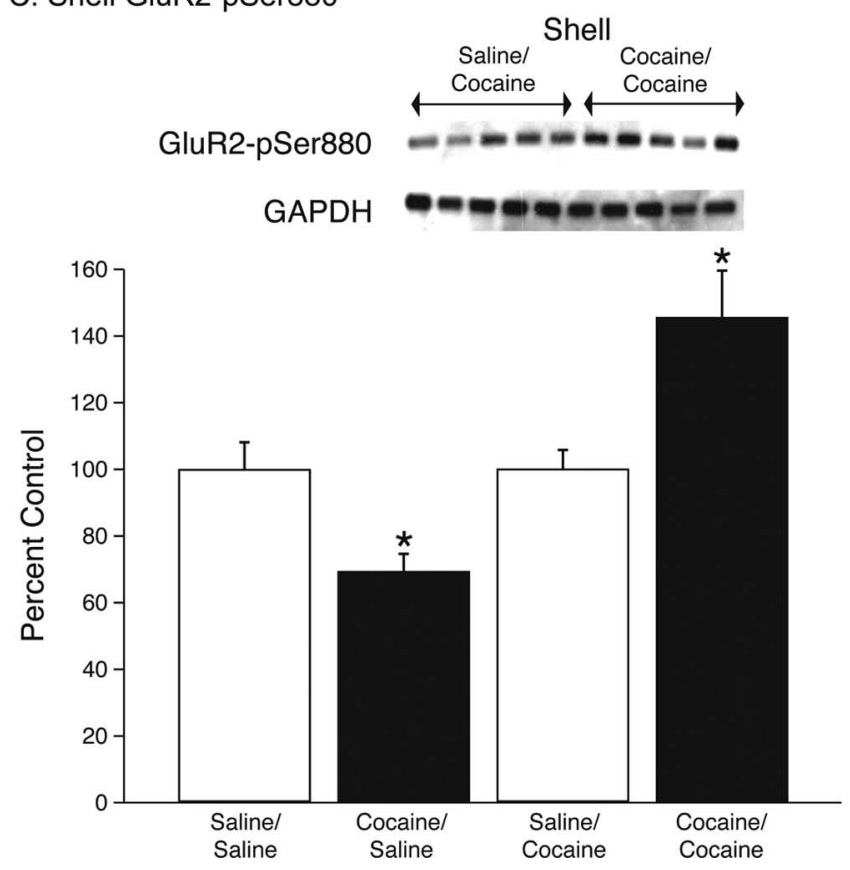

Figure 3. The reinstatement of cocaine seeking is associated with increased GluR2-pSer880 in the nucleus accumbens shell. $\boldsymbol{A}$, Schematic of a coronal brain section at the level of the anterior commissure (Paxinos and Watson, 1997). The black box approximates the region dissected for the core, whereas the gray box outlines the medial shell dissection. All dissections measures over brain region (core and shell). This analysis revealed a significant main effect of reinstatement $\left(F_{(1,20)}=15.68\right.$, $p<0.0008)$ and a significant self-administration $\times$ reinstatement interaction $\left(F_{(1,20)}=15.59, p<0.0008\right)$ with no other significant main effects or interactions. Subsequent pairwise comparisons (Fisher's LSD, $p<0.05$ ) showed that, in the shell, there was a significant difference between the cocaine/saline and saline/saline groups as well as a significant difference between the cocaine/cocaine group and both the saline/cocaine and saline/ saline treatments. Although there were trends toward similar effects in the core, post hoc tests (Fisher's LSD) revealed no significant differences. The number of subjects per group was as follows: saline $/$ saline $=7$, saline $/$ cocaine $=8$, cocaine $/$ saline $=4$, cocaine $/$ cocaine $=5$.

\section{Reinstatement of food seeking had no influence on the} expression of GluR2-pSer880 in the accumbens core and shell In these experiments, rats were trained to self-administer food or rats were yoked to the self-administration animals and received food pellets passively. During the reinstatement phase, presentation of food pellets produced robust reinstatement in the food self-administration rats but not the yoked controls (data not shown). GluR2-pSer880 in the accumbens core and shell during the reinstatement phase is shown in Figure $4 A$. The core and shell data were analyzed with separate mixed factors ANOVAs, with food self-administration/yoked food as the between subjects factor and GluR2-pSer880 as the within subjects factor. The results of these analyses revealed no significant interaction in the nucleus accumbens core $(p<0.9924)$ or shell $(p<0.7847)$. There were 4 subjects per group.

Noncontingent administration of cocaine did not produce significant changes in GluR2-pSer880 in either the nucleus accumbens core or shell

It is possible that the increased expression of GluR2-pSer880 observed in the nucleus accumbens shell is a result of repeated exposure to cocaine, and is not dependent on contingent selfadministration of cocaine. To investigate this possibility, we used a separate group of animals that were exposed to either yoked cocaine or yoked saline. After $6 \mathrm{~d}$ of "extinction," all animals were given a challenge injection of cocaine $(10 \mathrm{mg} / \mathrm{kg}$, i.p.), put in the behavioral boxes for $30 \mathrm{~min}$ and then immediately decapitated. These data are summarized in Figure $4 B$. There was no significant interaction observed in the nucleus accumbens core $(p<0.4761)$ or shell $(p<0.5170)$. There were 5 animals per group.

Intra-accumbal administration of Pep2-EVKI, which impairs AMPA receptor trafficking, attenuates the reinstatement of cocaine seeking

After cocaine self-administration, the animals in the shell experiment required $5.33 \pm 0.59 \mathrm{~d}$ to reach the extinction criteria.

$\leftarrow$

were bilateral. The insets represent some of the Western blots for GluR2-pSer880 and GAPDH (loading control) in the nucleus accumbens core and shell from the cocaine self-administration/ cocaine challenge injection and yoked saline/cocaine challenge injection treatments (yoked saline/saline challenge injection and cocaine self-administration/saline challenge injection blots not shown). Densitometric values from all Western blots were normalized to GAPDH and then expressed as percentage control. Results of these analyses are presented in $\boldsymbol{B}$ and $\boldsymbol{C}$. There were no significant differences among treatments in terms of GluR2-pSer880 ( $\boldsymbol{B}$ ) in the nucleus accumbens core. There were significant increases in GluR2-pSer880 $(\boldsymbol{C})$ in the cocaine/cocaine group relative compared with the saline/cocaine group and a significant decrease in the cocaine/saline relative to the saline/saline treatment in the nucleus accumbens shell. There were $4-8$ animals per treatment. 

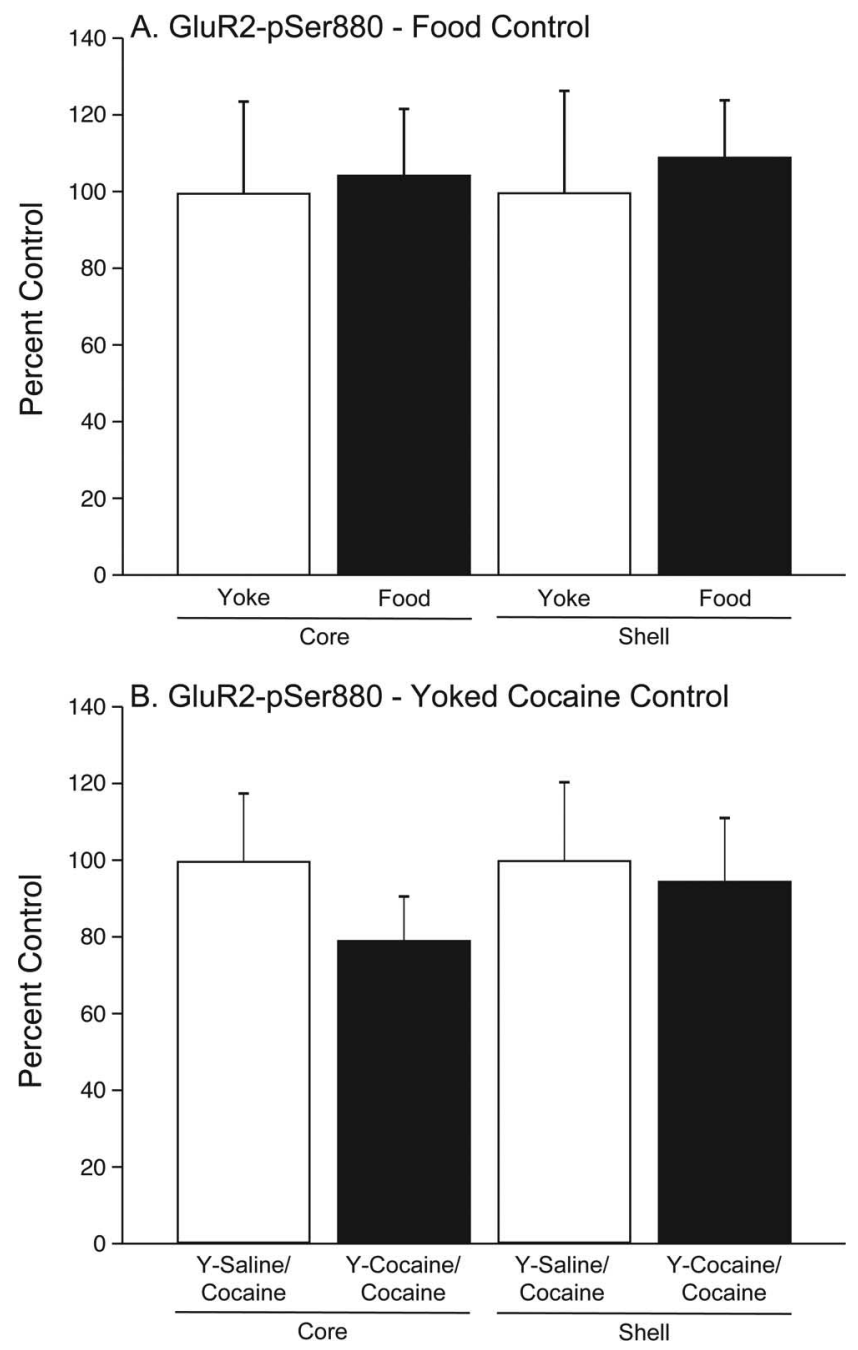

Figure 4. Reinstatement of food seeking or a cocaine challenge injection among yoked cocaine control rats has no influence on GluR2-pSer880 in the core or the shell of the nucleus accumbens. As depicted in $\boldsymbol{A}$, yoked pairs were trained to either self-administer sucrose pellets (food group) or received yoked sucrose pellet administrations passively (yoke group). The selfadministering rats were then extinguished, after which all animals were reinstated with remote sucrose pellet administration. There was no difference in GluR2-pSer880 in the nucleus accumbens core or shell of food self-administering rats versus yoked controls. There were 4 animals per group. The results summarized in $\boldsymbol{B}$ are from rats that received noncontingent yoked injections of saline (Y-Saline) or cocaine (Y-Cocaine). A subsequent systemic priming injection of 10 $\mathrm{mg} / \mathrm{kg}$ cocaine had no influence on GluR2-pSer880 in the accumbens core or shell of yoked cocaine relative to yoked saline subjects. There were 5 rats per treatment.

During the reinstatement phase of this experiment, saline $(n=$ $8)$, Pep2-EVKI $(n=8)$ or Pep2-SVKE $(n=10)$ was microinjected into the nucleus accumbens shell $1 \mathrm{~h}$ before a systemic injection of $10 \mathrm{mg} / \mathrm{kg}$ cocaine (intraperitoneal). The total active and inactive lever responses during reinstatement are graphed in Figure $5 A$. These data were analyzed with a mixed-factors MANOVA. All data from one subject were removed from the analysis because of excessive inactive lever presses ( 80 after saline treatment, well beyond two SDs above the mean for this group). The results of this analysis revealed significant main effects of treatment $\left(F_{(2,23)}\right.$ $=4.89, p<0.017)$ and lever $\left(F_{(1,23)}=72.089, p<0.0001\right)$ as well as a significant interaction between these factors $\left(F_{(2,23)}=3.774\right.$, $p<0.038$ ). Subsequent pairwise comparisons (Fisher's LSD, $p<$ 0.05 ) revealed significant differences between the Pep2-EVKI and both the saline and Pep2-SVKE treatments. The time courses of the active lever reinstatement data for the saline and Pep2-EVKI treatments are shown in Figure $5 B$. These data were analyzed with a mixed-factors MANOVA, with repeated measures over time. The results of this analysis indicated significant main effects of treatment $\left(F_{(1,14)}=29.621, p<0.0001\right)$ and time $\left(F_{(11,4)}=\right.$ 11.037, $p<0.0165)$ but no significant interaction between these factors $\left(F_{(11,4)}=2.515, p<0.1937\right)$. Despite the lack of a significant interaction, there were substantial differences between treatments during the 20 and 40 min time periods. As a control for nonspecific motor-suppressing effects, Pep2-EVKI $(n=10)$ or saline $(n=9)$ was microinjected into the accumbens shell $1 \mathrm{~h}$ before the reinstatement of food seeking. The data were as follows (mean \pm SEM): saline, $94.11 \pm 18.03$; Pep2-EVKI, $74.9 \pm 12.96$. The statistical analyses revealed that there was no significant main effect of treatment $\left(t_{(17)}=0.878, p<0.392\right)$. To demonstrate that the modified Pep2-EVKI used in these experiments was membrane permeable, this peptide was fluorescence-labeled (as described in the methods) and microinjected into the medial nucleus accumbens shell. Figure 5D includes a low-magnification photomicrograph demonstrating the extent of diffusion of Pep2EVKI after microinjection. Figure 5, $E$ and $F$, has higher magnification photomicrographs showing punctate labeling of accumbal cells and processes. The morphology of these labeled cells is consistent with that of medium spiny neurons, which account for $>90 \%$ of accumbal neurons. Pep2-EVKI and its saline vehicle also were administered into the accumbens core. The active lever data were as follows (mean \pm SEM): saline, $89.5 \pm 18.56, n=6$; Pep2-EVKI, $32.0 \pm 13.51, n=6$. These results were analyzed with a paired $t$ test, which revealed a significant treatment effect $\left(t_{(10)}\right.$ $=2.504, p<0.0333$ ). Thus, administration of Pep2-EVKI into either the nucleus accumbens shell or core attenuated the reinstatement of cocaine seeking.

\section{Discussion}

The present results indicate that (1) administration of the AMPA/ kainate receptor antagonist CNQX into either the core or the shell of the nucleus accumbens attenuates reinstatement of drug seeking after a cocaine challenge injection; (2) the reinstatement of cocaine seeking is associated with a significant increase in GluR2-pSer880 in the nucleus accumbens shell; and (3) disruption of the interaction between GluR2 and PICK1, which plays a critical role in the trafficking of GluR2-containing AMPA receptors, in the nucleus accumbens core and shell attenuates the reinstatement of cocaine seeking. Collectively, these data suggest that phosphorylation-dependent trafficking of GluR2containing AMPA receptors in the nucleus accumbens contributes significantly to the reinstatement of cocaine seeking.

\section{Role of nucleus accumbens AMPA receptors in the reinstatement of cocaine seeking}

A growing body of evidence indicates that activation of AMPA receptors in the nucleus accumbens plays a critical role in cocaine priming-induced reinstatement of drug seeking (Kalivas et al., 2005; Schmidt et al., 2005). The present data demonstrate that administration of an AMPA/kainate receptor antagonist into either the core or the shell of the nucleus accumbens attenuates the reinstatement of cocaine seeking, which suggests that activation of AMPA/kainate glutamate receptors in both the core and shell of the nucleus accumbens is necessary for the reinstatement of cocaine seeking. Consistent with these results, administration of AMPA into either the accumbens shell or core promotes the reinstatement of cocaine seeking (Ping et al., 2008). Previous work also suggests that increased glutamatergic transmission in the dorsal striatum may also play a role in drug craving in that ad- 

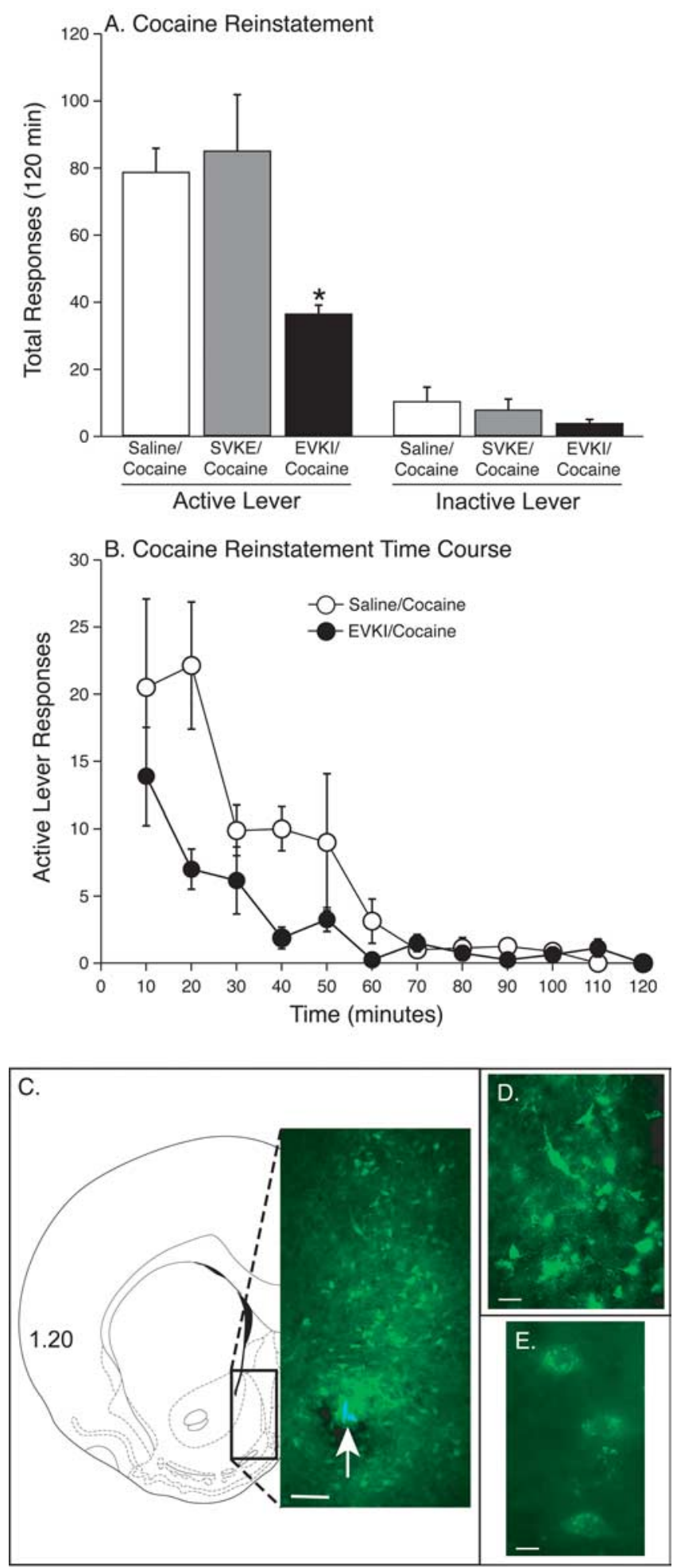

Figure 5. Intra-accumbal shell administration of Pep2-EVKI, which impairs AMPA receptor trafficking, attenuates the reinstatement of cocaine seeking. $\boldsymbol{A}$, The total active and inactive lever responses (mean $\pm \mathrm{SEM}$ ) after intra-accumbal shell microinjection of saline, Pep2-EVKI or Pep2-SVKE before a systemic priming injection of $10 \mathrm{mg} / \mathrm{kg}$ cocaine (intraperitoneal) during the reinstatement phase. Note the significant difference in active lever responses between Pep2EVKI/cocaine and the saline/cocaine treatments. There were $8-10$ rats per treatment. $\boldsymbol{B}$, The time courses of the active lever reinstatement data for the saline/cocaine and Pep2-EVKI/COcaine treatments. There were substantial differences between the saline/cocaine (open circles) and Pep2-EVKI treatments (closed circles) during the 20 and 40 min time periods. To demonstrate that the modified Pep2-EVKI used in these experiments was membrane permeable, this peptide was fluorescence-labeled (as described in Materials and Methods) and microinjected into the medial nucleus accumbens shell. C, Low-magnification photomicrograph demonstrat- ministration of an AMPA/kainate receptor antagonist into the dorsal striatum attenuated cocaine seeking using a second order schedule of reinforcement (Vanderschuren et al., 2005).

Although CNQX is a potent competitive antagonist of AMPA/ kainate receptors, at higher concentrations it can also act as an NMDA receptor antagonist via interactions with the glycine site (Birch et al., 1988; Sheardown, 1993). A growing literature indicates that glycine receptors play an important role in various psychostimulated-mediated behaviors (Shoaib et al., 1995; Mead and Stephens, 1999; Papp et al., 2002; Bäckström and Hyytiä, 2006) (but see Hyytiä et al., 1999; Kotlińska and Biała, 1999). Similar doses of CNQX as those used in the current study have been used extensively to study the role of AMPA/kainate receptors in cocaine self-administration and the reinstatement of cocaine-seeking behavior (Bell et al., 2000; Cornish and Kalivas, 2000; See et al., 2001; Park et al., 2002; Bäckström and Hyytiä, 2003, 2007). Interestingly, when administered directly into the accumbens shell, an NMDA receptor antagonist reinstated cocaine-seeking behavior (Park et al., 2002; Famous et al., 2007), whereas the present results indicate that intra-accumbal administration of CNQX attenuates the reinstatement of cocaine seeking. Although this evidence, taken together, suggests that CNQX acts primarily as an AMPA/kainate receptor antagonist at the doses used in the current behavioral experiments, the action of this drug at NMDA receptors cannot be ruled out.

\section{Changes in expression of GluR2-pSer880 in the nucleus} accumbens during the reinstatement of cocaine seeking The present data indicate that the reinstatement of cocaine seeking was associated with significantly increased GluR2-pSer880, a PKC phosphorylation site, in the shell subregion of the nucleus accumbens, although there was a marked trend toward an increase in the accumbens core as well. Moreover, the current results demonstrate that increases in GluR2-pSer880 receptor subunit expression in the nucleus accumbens are specific to animals undergoing reinstatement of cocaine-seeking behavior because no significant changes in GluR2-pSer880 were observed in the shell or core of yoked cocaine rats or during the reinstatement of food-seeking behavior. In contrast, GluR2 subunits appear to play an important role in food reward because AMPA receptor antagonists increase feeding when administered into the nucleus accumbens shell (Kelley, 1999) and GluR2 knock-out mice do not display a conditioned place preference for food (Mead et al., 2005). It seems likely that the reinforcer-specific changes in GluR2-pSer880 in the accumbens shell observed in the current experiments are attributable to the fact that the neuronal circuits underlying cocaine and food seeking behaviors are at least partially segregated (Carelli and Wondolowski, 2003; Horvath and Diano, 2004).

The present findings suggest that the reinstatement of cocaine seeking is associated with a PKC-dependent increase in the phosphorylation of GluR2 subunits in the nucleus accumbens shell and possibly core. To our knowledge, no studies have previously examined a potential role for accumbal PKC in the reinstatement of cocaine seeking. However, repeated systemic cocaine injections increased the phosphorylation of some, but not all, iso-

$\leftarrow$

ing the extent of diffusion of fluorescence-labeled Pep2-EVKI after microinjection into accumbens shell. $\boldsymbol{D}, \boldsymbol{E}$, Higher magnification photomicrographs from $\boldsymbol{C}$ showing punctate labeling of nucleus accumbens shell cells and processes. The white arrow indicates the site of the microinjection. Scale bars: $\boldsymbol{C}, 200 \mu \mathrm{m} ; \boldsymbol{D}, 60 \mu \mathrm{m} ; \boldsymbol{E}, 15 \mu \mathrm{m}$. 
forms of PKC in the nucleus accumbens (Steketee et al., 1998; Chen et al., 2007). In addition, intra-accumbal administration of a PKC inhibitor attenuated conditioned place preference induced by the psychostimulant amphetamine (Aujla and Beninger, 2003). Interestingly, PKC-induced phosphorylation of GluR2Ser880 promotes the internalization of GluR2-containing AMPA receptors (Chung et al., 2000), which suggests that changes in AMPA receptor trafficking may contribute to the reinstatement of cocaine seeking.

\section{Trafficking of GluR2-containing AMPA receptors in the nucleus accumbens and the reinstatement of cocaine seeking} The C-terminal domains of the GluR2 AMPA receptor subunit are cytosolic and contain all of the known GluR2 phosphorylation sites (Song and Huganir, 2002). GluR2 C-terminal domains also contain recognition motifs that are required for interactions with PICK1 (Song and Huganir, 2002), a protein that plays a critical role in the trafficking and targeting of AMPA receptors containing these subunits (Hanley, 2006; Ziff, 2007). Specifically, recent results indicate that $\mathrm{PKC}$-induced phosphorylation of GluR2 subunits at Ser880 and the subsequent association of GluR2 with PICK1 results in rapid internalization of GluR2containing AMPA receptors (Chung et al., 2000; Perez et al., 2001; Collingridge et al., 2004; Terashima et al., 2004) (but see, Gardner et al., 2005; Liu and Cull-Candy, 2005). To further assess the potential role of accumbal AMPA receptors in the reinstatement of cocaine seeking, we used a peptide, Pep2-EVKI, that mimics $\mathrm{C}$ terminus residues of GluR2, thereby disrupting the interaction between GluR2 subunits and PICK1 (Daw et al., 2000). Our results indicate that the administration of Pep2-EVKI directly into the nucleus accumbens shell or core attenuates the reinstatement of cocaine seeking, which suggests that impairing the trafficking of GluR2-containing AMPA receptors in both subregions of the nucleus accumbens disrupts the reinstatement of cocaine seeking. Similarly, intra-accumbal administration of a peptide (Tat-GluR2 $2_{3 Y}$ ) that specifically blocks regulated but not constitutive endocytosis of GluR2-containing AMPA receptors attenuates the expression of behavioral sensitization to amphetamine (Brebner et al., 2005).

The present findings are consistent with recent work demonstrating that the trafficking of AMPA receptors is influenced by a history of cocaine exposure. Thus, there was a redistribution of accumbal GluR1 and GluR2 AMPA receptor subunits to the cell surface 2 weeks after a regimen of systemic cocaine injections (Boudreau and Wolf, 2005; Boudreau et al., 2007). In contrast, a cocaine challenge injection resulted in GluR1 and GluR2 internalization in the nucleus accumbens of cocaine-experienced rats (Boudreau et al., 2007). Consistent with these findings, repeated psychostimulant administration has been reported to increase AMPA-mediated synaptic transmission and plasticity ( $\mathrm{Li}$ and Kauer, 2004; Yao et al., 2004; Kourrich et al., 2007), whereas a cocaine challenge injection reversed this augmentation of excitatory transmission in the nucleus accumbens (Kourrich et al., 2007). Thus, repeated cocaine administration results in bidirectional plasticity in the nucleus accumbens (Boudreau et al., 2007; Kourrich et al., 2007). Consistent with these findings, the current results indicate that, among rats with a history of cocaine selfadministration, a saline challenge injection was associated with a decrease, whereas a cocaine challenge injection resulted in an increase, in GluR2-pSer880 in the nucleus accumbens shell (with similar, albeit less pronounced, effects in the core). The mechanisms underlying psychostimulant-induced changes in accumbal synaptic strength have not been completely characterized, but initial evidence indicates that the inhibition of clathrindependent endocytosis of GluR2-containing AMPA receptors contributes to this process (Brebner et al., 2005).

Our results suggest that preventing the removal of GluR2containing AMPA receptors from synapses in the nucleus accumbens shell attenuates the reinstatement of cocaine seeking. Recent evidence, in contrast, indicates that increases in GluR1-mediated excitatory transmission in the accumbens shell promotes both cocaine priming- and cue-induced reinstatement of cocaine seeking (Anderson et al., 2008; Conrad et al., 2008), which suggests that GluR1 and GluR2 subunits in the nucleus accumbens shell may play differential roles in the reinstatement of cocaine seeking.

\section{Conclusions}

The present results indicate that changes in AMPA receptormediated glutamate transmission in both the core and shell subregions of the nucleus accumbens contribute significantly to cocaine priming-induced reinstatement of drug seeking. During the reinstatement of cocaine seeking increased phosphorylation of GluR2 at Ser880 was observed in the nucleus accumbens, which promotes the removal of GluR2-containing AMPA receptors from synapses (see also Boudreau and Wolf, 2005; Boudreau et al., 2007). Consistent with these findings, impairing the internalization of GluR2 receptor subunits in the nucleus accumbens attenuated the reinstatement of cocaine seeking. Together, these results suggest that drug craving induced by re-exposure to cocaine is triggered by increases in the endocytosis of GluR2containing AMPA receptors in the nucleus accumbens.

\section{References}

Anderson SM, Bari AA, Pierce RC (2003) Administration of the D1-like dopamine receptor antagonist SCH-23390 into the medial nucleus accumbens shell attenuates cocaine priming-induced reinstatement of drug-seeking behavior in rats. Psychopharmacology (Berl) 168:132-138.

Anderson SM, Famous KR, Sadri-Vakili G, Kumaresan V, Schmidt HD, Bass CE, Terwilliger EF, Cha JH, Pierce RC (2008) CaMKII: a biochemical bridge linking accumbens dopamine and glutamate systems in cocaine seeking. Nat Neurosci 11:344-353.

Aujla H, Beninger RJ (2003) Intra-accumbens protein kinase C inhibitor NPC 15437 blocks amphetamine-produced conditioned place preference in rats. Behav Brain Res 147:41-48.

Bäckström P, Hyytiä P (2003) Attenuation of cocaine-seeking behaviour by the AMPA/kainate receptor antagonist CNQX in rats. Psychopharmacology (Berl) 166:69-76.

Bäckström P, Hyytiä P (2006) Ionotropic and metabotropic glutamate receptor antagonism attenuates cue-induced cocaine seeking. Neuropsychopharmacology 31:778-786.

Bäckström P, Hyytiä P (2007) Involvement of AMPA/kainate, NMDA, and $\mathrm{mGlu} 5$ receptors in the nucleus accumbens core in cue-induced reinstatement of cocaine seeking in rats. Psychopharmacology (Berl) 192:571-580.

Bell K, Duffy P, Kalivas PW (2000) Context-specific enhancement of glutamate transmission by cocaine. Neuropsychopharmacology 23:335-344.

Berk K (1987) Computing for incomplete repeated measures. Biometrics 43:385-398.

Bernard V, Somogyi P, Bolam JP (1997) Cellular, subcellular, and subsynaptic distribution of AMPA-type glutamate receptor subunits in the neostriatum of the rat. J Neurosci 17:819-833.

Birch PJ, Grossman CJ, Hayes AG (1988) 6,7-Dinitro-quinoxaline-2,3-dion and 6-nitro,7-cyano-quinoxaline-2,3-dion antagonise responses to NMDA in the rat spinal cord via an action at the strychnine-insensitive glycine receptor. Eur J Pharmacol 156:177-180.

Boudreau AC, Wolf ME (2005) Behavioral sensitization to cocaine is associated with increased AMPA receptor surface expression in the nucleus accumbens. J Neurosci 25:9144-9151.

Boudreau AC, Reimers JM, Milovanovic M, Wolf ME (2007) Cell surface AMPA receptors in the rat nucleus accumbens increase during cocaine withdrawal but internalize after cocaine challenge in association with 
altered activation of mitogen-activated protein kinases. J Neurosci 27:10621-10635.

Brebner K, Wong TP, Liu L, Liu Y, Campsall P, Gray S, Phelps L, Phillips AG, Wang YT (2005) Nucleus accumbens long-term depression and the expression of behavioral sensitization. Science 310:1340-1343.

Carelli RM, Wondolowski J (2003) Selective encoding of cocaine versus natural rewards by nucleus accumbens neurons is not related to chronic drug exposure. J Neurosci 23:11214-11223.

Chen Q, Lee TH, Wetsel WC, Sun QA, Liu Y, Davidson C, Xiong X, Ellinwood EH, Zhang X (2007) Reversal of cocaine sensitization-induced behavioral sensitization normalizes $\mathrm{GAD}(67)$ and $\mathrm{GABA}(\mathrm{A})$ receptor alpha2 subunit expression, and PKC zeta activity. Biochem Biophys Res Commun 356:733-738.

Chung HJ, Xia J, Scannevin RH, Zhang X, Huganir RL (2000) Phosphorylation of the AMPA receptor subunit GluR2 differentially regulates its interaction with PDZ domain-containing proteins. J Neurosci 20:7258-7267.

Collingridge GL, Isaac JT, Wang YT (2004) Receptor trafficking and synaptic plasticity. Nat Rev Neurosci 5:952-962.

Conrad KL, Tseng KY, Uejima JL, Reimers JM, Heng LJ, Shaham Y, Marinelli M, Wolf ME (2008) Formation of accumbens GluR2-lacking AMPA receptors mediates incubation of cocaine craving. Nature 454:118-121.

Cornish JL, Kalivas PW (2000) Glutamate transmission in the nucleus accumbens mediates relapse in cocaine addiction. J Neurosci 20:RC89.

Daw MI, Chittajallu R, Bortolotto ZA, Dev KK, Duprat F, Henley JM, Collingridge GL, Isaac JT (2000) PDZ proteins interacting with C-terminal GluR2/3 are involved in a PKC-dependent regulation of AMPA receptors at hippocampal synapses. Neuron 28:873-886.

Famous KR, Schmidt HD, Pierce RC (2007) When administered into the nucleus accumbens core or shell, the NMDA receptor antagonist AP-5 reinstates cocaine-seeking behavior in the rat. Neurosci Lett 420:169-173.

Gardner SM, Takamiya K, Xia J, Suh JG, Johnson R, Yu S, Huganir RL (2005) Calcium-permeable AMPA receptor plasticity is mediated by subunitspecific interactions with PICK1 and NSF. Neuron 45:903-915.

Gold SJ, Ambros-Ingerson J, Horowitz JR, Lynch G, Gall CM (1997) Stoichiometries of AMPA receptor subunit mRNAs in rat brain fall into discrete categories. J Comp Neurol 385:491-502.

Hanley JG (2006) Molecular mechanisms for regulation of AMPAR trafficking by PICK1. Biochem Soc Trans 34:931-935.

Heimer L, Alheid GF, de Olmos JS, Groenewegen HJ, Haber SN, Harlan RE, Zahm DS (1997) The accumbens: beyond the core-shell dichotomy. J Neuropsychiatry Clin Neurosci 9:354-381.

Hemby SE, Tang W, Muly EC, Kuhar MJ, Howell L, Mash DC (2005) Cocaine-induced alterations in nucleus accumbens ionotropic glutamate receptor subunits in human and non-human primates. J Neurochem 95:1785-1793.

Horvath TL, Diano S (2004) The floating blueprint of hypothalamic feeding circuits. Nat Rev Neurosci 5:662-667.

Hyytiä P, Bäckström P, Liljequist S (1999) Site-specific NMDA receptor antagonists produce differential effects on cocaine self-administration in rats. Eur J Pharmacol 378:9-16.

Kalivas PW, Volkow N, Seamans J (2005) Unmanageable motivation in addiction: a pathology in prefrontal-accumbens glutamate transmission. Neuron 45:647-650.

Kelley AE (1999) Functional specificity of ventral striatal compartments in appetitive behaviors. Ann N Y Acad Sci 877:71-90.

Kotlińska J, Biała G (1999) Effects of the NMDA/glycine receptor antagonist, L-701,324, on morphine- and cocaine-induced place preference. Pol J Pharmacol 51:323-330.

Kourrich S, Rothwell PE, Klug JR, Thomas MJ (2007) Cocaine experience controls bidirectional synaptic plasticity in the nucleus accumbens. J Neurosci 27:7921-7928.

Li P, Kerchner GA, Sala C, Wei F, Huettner JE, Sheng M, Zhuo M (1999) AMPA receptor-PDZ interactions in facilitation of spinal sensory synapses. Nat Neurosci 2:972-977.

Li Y, Kauer JA (2004) Repeated exposure to amphetamine disrupts dopaminergic modulation of excitatory synaptic plasticity and neurotransmission in nucleus accumbens. Synapse 51:1-10.

Liu SJ, Cull-Candy SG (2005) Subunit interaction with PICK and GRIP controls $\mathrm{Ca} 2+$ permeability of AMPARs at cerebellar synapses. Nat Neurosci 8:768-775.

Lu L, Grimm JW, Shaham Y, Hope BT (2003) Molecular neuroadaptations in the accumbens and ventral tegmental area during the first 90 days of forced abstinence from cocaine self-administration in rats. J Neurochem 85:1604-1613.

Maldonado-Irizarry CS, Swanson CJ, Kelley AE (1995) Glutamate receptors in the nucleus accumbens shell control feeding behavior via the lateral hypothalamus. J Neurosci 15:6779-6788.

McFarland K, Lapish CC, Kalivas PW (2003) Prefrontal glutamate release into the core of the nucleus accumbens mediates cocaine-induced reinstatement of drug-seeking behavior. J Neurosci 23:3531-3537.

Mead AN, Stephens DN (1999) CNQX but not NBQX prevents expression of amphetamine-induced place preference conditioning: a role for the glycine site of the NMDA receptor, but not AMPA receptors. J Pharmacol Exp Ther 290:9-15.

Mead AN, Brown G, Le Merrer J, Stephens DN (2005) Effects of deletion of gria1 or gria2 genes encoding glutamatergic AMPA-receptor subunits on place preference conditioning in mice. Psychopharmacology (Berl) 179:164-171

Papp M, Gruca P, Willner P (2002) Selective blockade of drug-induced place preference conditioning by ACPC, a functional NDMA-receptor antagonist. Neuropsychopharmacology 27:727-743.

Park WK, Bari AA, Jey AR, Anderson SM, Spealman RD, Rowlett JK, Pierce RC (2002) Cocaine administered into the medial prefrontal cortex reinstates cocaine-seeking behavior by increasing AMPA receptor-mediated glutamate transmission in the nucleus accumbens. J Neurosci 22:2916-2925.

Paxinos G, Watson C (1997) The rat brain in stereotaxic coordinates. New York: Academic.

Perez JL, Khatri L, Chang C, Srivastava S, Osten P, Ziff EB (2001) PICK1 targets activated protein kinase Calpha to AMPA receptor clusters in spines of hippocampal neurons and reduces surface levels of the AMPAtype glutamate receptor subunit 2. J Neurosci 21:5417-5428.

Ping A, Xi J, Prasad BM, Wang MH, Kruzich PJ (2008) Contributions of nucleus accumbens core and shell GluR1 containing AMPA receptors in AMPA- and cocaine-primed reinstatement of cocaine-seeking behavior. Brain Res 1215:173-182.

Schmidt HD, Anderson SM, Famous KR, Kumaresan V, Pierce RC (2005) Anatomy and pharmacology of cocaine priming-induced reinstatement of drug seeking. Eur J Pharmacol 526:65-76.

See RE, Kruzich PJ, Grimm JW (2001) Dopamine, but not glutamate, receptor blockade in the basolateral amygdala attenuates conditioned reward in a rat model of relapse to cocaine-seeking behavior. Psychopharmacology (Berl) 154:301-310.

Sheardown MJ (1993) The pharmacology of AMPA receptors and their antagonists. Stroke 24:I146-147; discussion I153-144.

Shoaib M, Shippenberg TS, Goldberg SR, Schindler CW (1995) Behavioral studies with the glycine partial agonist (+)-HA966 on cocaine-induced locomotor activity and reinforcement. Behav Pharmacol 6:568-576.

Song I, Huganir RL (2002) Regulation of AMPA receptors during synaptic plasticity. Trends Neurosci 25:578-588.

Steketee JD, Rowe LA, Chandler LJ (1998) The effects of acute and repeated cocaine injections on protein kinase $\mathrm{C}$ activity and isoform levels in dopaminergic brain regions. Neuropharmacology 37:339-347.

Sutton MA, Schmidt EF, Choi KH, Schad CA, Whisler K, Simmons D, Karanian DA, Monteggia LM, Neve RL, Self DW (2003) Extinction-induced upregulation in AMPA receptors reduces cocaine-seeking behaviour. Nature 421:70-75.

Tang W, Wesley M, Freeman WM, Liang B, Hemby SE (2004) Alterations in ionotropic glutamate receptor subunits during binge cocaine selfadministration and withdrawal in rats. J Neurochem 89:1021-1033.

Terashima A, Cotton L, Dev KK, Meyer G, Zaman S, Duprat F, Henley JM, Collingridge GL, Isaac JT (2004) Regulation of synaptic strength and AMPA receptor subunit composition by PICK1. J Neurosci 24:5381-5390.

Vanderschuren LJ, Di Ciano P, Everitt BJ (2005) Involvement of the dorsal striatum in cue-controlled cocaine seeking. J Neurosci 25:8665-8670.

Yao WD, Gainetdinov RR, Arbuckle MI, Sotnikova TD, Cyr M, Beaulieu JM, Torres GE, Grant SG, Caron MG (2004) Identification of PSD-95 as a regulator of dopamine-mediated synaptic and behavioral plasticity. Neuron 41:625-638.

Zhao K, Luo G, Zhao GM, Schiller PW, Szeto HH (2003) Transcellular transport of a highly polar $3+$ net charge opioid tetrapeptide. J Pharmacol Exp Ther 304:425-432.

Ziff EB (2007) TARPs and the AMPA receptor trafficking paradox. Neuron 53:627-633. 